The Journal of Academic Librarianship, 2007, Vol. 33, No. 1, p. 56-66.

ISSN: 0099-1333 (print) 1879-1999(online)

DOI: $10.1016 /$ j.acalib.2006.08.008

http://www.sciencedirect.com/science/journal/00991333/33/1

http://www.sciencedirect.com/science/article/pii/S0099133306001601

Copyright (c) 2007 Elsevier Inc. All rights reserved.

\title{
Open WorldCat and Its Impact on Academic Libraries
}

\author{
by Magda El-Sherbini
}

\begin{abstract}
This paper analyzes librarians' reactions to the Open OCLC WorldCat. A detailed survey was sent to ARL libraries to explore what, if anything, the libraries are currently doing to prepare for these changes and how they plan to cope with the probability of having all their records open to the whole world. Survey findings indicate that most of the ARL member institutions are not making immediate preparations to cope with issues that have not yet emerged and they will continue to provide access to materials based on priorities dictated by current needs and available resources.
\end{abstract}

\section{Introduction}

During the last few years, technology has been advancing at a very rapid pace. Introduction of the World Wide Web in the 1990s, subsequent development of effective search engines such as Yahoo! and Google, and advances in digital technologies helped create a virtual universe of information that is available to all users via the Internet. Information that is made available through the Internet can now be accessed from homes, offices, cafes, airplanes, etc. As traditional library users became increasingly dependent on instant information available via the Internet, they began to lose interest in some of the services that were traditionally offered by libraries.

Librarians began to feel the impact of these changes and initiated debates on how technology is affecting their business and what the response to this challenge might be. In response to these changes in user behavior on the academic level, OCLC and RLG have recently gone beyond making their union catalogs available to library users and made the contents of their databases available to the public at large via the Web.

The present study was undertaken to explore the degree to which libraries and librarians are committed to the idea of having their collections available through the Internet. A large part of the paper focuses on the quality of records in the library OPACs and the potential need to have these records upgraded or enriched, so the remote user can assess their usefulness. The second important theme addresses the issue of un-cataloged collections and the digital document repositories. At this time most of these materials are not represented in the library OPACs and this study attempts to determine if libraries are committed to the idea of providing full access to all of their institutional materials. Digitizing library collections and institutional repositories are addressed in the final parts of the discussion. These two sets of materials have existed outside the traditional library catalogs and the author will attempt to determine how libraries perceive the future of these collections. 


\section{Background}

Recent technological developments in the area of information processing and dissemination have made a profound impact on ways in which information is accessed. Explosion of information that is available through the Internet is making a huge impact on libraries and their users.

Information that is available through the Internet ranges from scholarly information on the one hand, to answers to quick questions, such as a recipe for a pound cake, on the other. Many academic Web searchers and users prefer to use the two leading search engines, Yahoo! and Google, rather than the library OPAC. This is due, in part, to the flexibility of the Web, which is rapidly becoming an all-purpose tool that includes personal communication as well. As Stephen Abram mentioned in his article "For users who cry out for online discussions, communities of practice, group and individual blogs, and connections through social networking software, Google already offers Blogger, Google Groups, and the new Orkut beta, already a pretty advanced social networking tool." ${ }^{1}$

In addition to speed and personal communication, today's users are also becoming dependent on the convenient manner in which information can be accessed and delivered. As Judy Luther points out in her article, "Google has radically changed users' expectations and redefined the experience of those seeking information. For many searchers, quality of the results matter less than the process - they just expect the process to be quick and easy."

Library content has, for the most part, been excluded from the Internet revolution. Wealth of bibliographic information that is contained in major bibliographic utilities such as the OCLC WorldCat and the Research Libraries Group catalog was available only at the library. Until recently, only those institutions which use a cataloging interface to the WorldCat database or which subscribe to the WorldCat database via FirstSearch products were able to provide WorldCat access to their users. This left the valuable resources of world libraries outside the emerging information mainstream that we now call The Web. Initial remedies to this situation were offered by RLG and OCLC.

On September 22, 2003, RLG launched their "RedLight-Green" pilot, to support undergraduates using the Web. ${ }^{3}$ RedLightGreen is a free resource that helps the user to find important books for research, check their availability at the library, and to create citations. It delivers information from RLG members about more than 130 million books for education and research, and it links students back to their campus libraries for the books they select. RedLightGreen allows any library with a Web-based catalog (with URL-supported search syntax) to be linked, regardless of whether the institution is an RLG member. This innovation provides access to bibliographic and location information on library materials via the Web.

OCLC was also among those institutions that began to seek solutions. Their response was to bring the library to the Internet user by opening the WorldCat database to Web searchers through Internet search engines such as Google and Yahoo! and other partners. To use these search services, patrons would simply enter a search phrase to locate an item. Through the "Find in a Library" function, the user could then enter their postal code to locate the item at a participating library in their city, region or country.

On October 27, 2003, OCLC announced that it would begin a pilot project to test the feasibility of opening the WorldCat database to Google and other search engines. ${ }^{4}$ The idea behind this project was to utilize available technology to integrate library collections with the Internet and make these materials available to Web users. By taking advantage of the popular 
search engines, libraries would increase their visibility to the broad user community and make information about their treasured collections available to the world via the Internet. The experiment with Google was a success, and nearly a year later, on July 2004, OCLC expanded its pilot project to locate libraries materials to Yahoo! search. ${ }^{5}$ On October 11, 2004, OCLC decided to open the entire collection of their records. ${ }^{6}$

Another step toward a further integration of library resources was taken at the time of reviewing this paper. On May 2006, Jay Jordan, President and CEO of OCLC, announced that OCLC and RLG had signed a definitive agreement to combine the two organizations. ${ }^{7}$ If this agreement is approved by RLG membership, OCLC will purchase the assets and assume certain liabilities of RLG, effective July 1, 2006. This merger of RLG with OCLC appears to be another major step in the process of integrating library resources and is likely to have an impact on WorldCat and its users.

\section{Literature Review}

The subject of opening access to the OCLC's WorldCat database through Google is fairly new and the author found relatively little literature that addressed the question directly. Most of what is found in literature consists of announcements, comments on user's perspective, news stories and reports, and exchanges of e-mails.

OCLC's own Web site is the primary and authoritative source of information on this topic. It contains valuable information on topics such as: Open WorldCat Program, ${ }^{8}$ Quick Facts about the Open WorldCat Pilot, ${ }^{9}$ How the Open WorldCat Pilot Works, ${ }^{10}$ Open WorldCat Pilot: Frequently Asked Questions," User-Contributed Content Pilot. ${ }^{12}$ These materials provide most of the current information about the project.

An interesting comparison between RedLightGreen and Open WorldCat is provided in a recent article by David Mattison. ${ }^{13}$ In his comparison, the author addressed both the strengths and weaknesses of both projects, the target audience, source data and basic searching methods, advanced searching methods, library holdings, and search personalization options. He concluded that both projects offer great information to users; however, Open WorldCat works best when users are looking for a specific title and need to know whether a library holds it or not, whereas RedLightGreen, with its research focus, displays many titles at once, with no capability of indicating whether a library owns any one title.

Various aspects of searching the WorldCat data in a Web browser environment are discussed in two papers by Nancy O'Neill and Gary Price. ${ }^{14}$ In Open WorldCat: A User's Perspective, O'Neill addressed issues related to searching the WorldCat items in Google and Yahoo! and how different search techniques can provide different results, or no results. Price raised important points about the number of mouse clicks that are required to locate a specific item and how that might impact user behavior. He also raised the question - "Why doesn't OCLC make subject headings viewable and hyperlinked." This issue in particular was later resolved by making subject headings visible and hot-linked. This feature, as Price emphasized, will help in limiting the result of a search to only Open WorldCat records. In another paper by Gary Price

and Steven Cohn point out that OCLC must improve subject access to materials. ${ }^{15}$ After running several subject searches on random topics, the authors received poor results at both Yahoo! and Google.

Paula Wilson raises important questions about providing Internet access to the WorldCat 
database in her paper. ${ }^{6}$ Wilson discusses how Open WorldCat works, the benefits of having library materials accessible via the major search engines and discusses some issues of concern.

Any number of other short articles and announcements could be mentioned in this review, but most of them do not add substantially to the discussion of this topic. As statistical data about the use of WorldCat by the Internet users become available, further research will be conducted. At this time, librarians and researchers are not offering speculation about ways in which this change is going to impact library operations and the survey conducted by this author attempts to address some of these issues.

\section{Research Methodology}

Since the opening of OCLC's WorldCat via Google and Yahoo! librarians began to raise questions about the impact this development would have on libraries and their operations? Since libraries are the feeder of the WorldCat database, would they have a role in adapting and facilitating this important transformation of the WorldCat database?

To provide a more in-depth analysis of the issues, the author developed a survey (Appendix A), which was distributed electronically via Zoomerang to the heads of cataloging departments or to assistant directors of technical services or their equivalents at 123 Association of Research Libraries (ARL) member institutions. ${ }^{17}$ A cover letter was sent along with the survey to outline the purpose of the study, and to provide instructions for completing the survey (Appendix B). The letter assured participants that the result would be reported in this study.

The survey was initially distributed informally to a small number of ARL librarians for their input, proofreading, and for clarity. Based on their comments and feedback, the survey was revised. ARL academic libraries formed the population sample for this study, since these institutions represent a well-defined group of libraries with sufficiently large collections.

A number of obstacles were encountered in the process. It was unexpectedly difficult to create a mailing list of the ARL recipients and it was very difficult to find an address or an email of some recipients. Reliance on institutional Web sites was a very disappointing experience. On a number of occasions, the author had to resort to the telephone to establish identities of heads of cataloging or assistant directors for various departments. Names, titles, and address information changed as individuals changed positions, retired, or left their positions for other reasons, and online information was not updated. The survey was distributed, followed by two reminders sent within ten days of each other.

The survey response was 54 (43.9 percent) out of 123 ARL libraries responding. Although a better response rate could have been expected, given the timeliness of this topic, the author considers the fifty-four responses acceptable.

Some questions in the survey required a yes or a no response. All of the questions, however, offer opportunity for comments and opinions. The survey consisted of twenty questions. Some of the questions (Questions 19 and 20) were of general nature and the data obtained are not discussed in this paper in detail. Other questions, pertaining to un-cataloged collections provide interesting detail that falls outside the scope of this paper. Data gathered in this part of the survey will be analyzed and discussed at a future time. 


\section{Survey Results}

Survey results will be grouped in four parts and discusses as follows:

Part one: Provides information about the quality of records; commitments of libraries to cataloging according to standards; cataloging staffing level; and using additional services such as vendor records.

Part two: Addresses the issue of un-cataloged collections; commitment of libraries to catalog these materials; the level of cataloging of these material; enriching bibliographic records; and whether libraries are planning to add their entire collections to the Open WorldCat.

Part three: Provides information about library repositories and asks if libraries are willing to integrate their repository materials into their OPACs and to Open WorldCat.

Part four: Provides information about libraries' vision and if they are foreseeing a time when all library collections will be digitized.

\section{Part One: Quality of Records in WorldCat}

There is an underlying assumption that opening of library catalogs through the Internet will increase the library presence on the Web and in the user community. What this implies is an increased use of libraries by current patrons and new, Web-based patrons, who will now find library materials useful and desirable. This survey attempts to ascertain what steps libraries are planning to take to provide the quality of catalog records that would assure full access to their collections in the Web environment.

Quality of cataloging records has always been the determining factors in providing effective access to materials. The library community has always taken great care in developing cataloging standards and professional training to assure that quality would be maintained. As the opportunity to move library records to the Web environment arises, it is useful to revisit these issues and determine whether changes need to be made to meet this new challenge.

\section{Standards}

Table 1 of the survey is intended to measure the level and commitment to various cataloging standards, by asking which cataloging standards are currently in use by the ARL members. The response shows that all ARL libraries (100 percent) continue to use traditional resources for cataloging. These resources include the Anglo-American Cataloging Rules, Second edition revised (AACR2 rev.), Bibliographic Machine-Readable Cataloging (MARC21), Library of Congress Subject Headings (LCSH), and Library of Congress Classification (LCC). However, there are new standards that are being adapted and used to catalog digital materials. Dublin Core (DC) is used by 41 percent of the respondents who use it to catalog library Web content and archived images. Table 1 also shows that 18.5 percent of ARL libraries use other metadata, such as Encoding Archival Description (EAD), Federal Geo graphic Data Committee (FGDC), 
Extensible Markup Language (XML), Text Encoding Initiative (TEI), and Visual Resources Associations (VRA) Core. As for the Functional Requirements for Bibliographic Records (FRBR), 4.5 percent of libraries responded that they would adapt it when it is incorporated into the Resources Discovery and Access (RDA, formerly AACR2 revised).

Table 1. What Cataloging Standards Does Your Library Use for Cataloging?

\begin{tabular}{|c|c|c|c|c|}
\hline & \multicolumn{2}{|c|}{ Yes } & \multicolumn{2}{|c|}{ No } \\
\hline & $N$ & $\%$ & $N$ & $\%$ \\
\hline AACR 2 rev & 54 & 100 & 0 & 0 \\
\hline LSCH & 54 & 100 & 0 & 0 \\
\hline LC Classification & 54 & 100 & 0 & 0 \\
\hline DDC & 2 & 3.7 & 52 & 96.2 \\
\hline UDC & 0 & 0 & 0 & 0 \\
\hline MARC21 & 52 & 96.2 & 2 & 0.23 \\
\hline FRBR & 5 & 4.5 & 49 & 90.7 \\
\hline Dublin Core & 22 & 41 & 32 & 59.2 \\
\hline Others & 10 & 18.5 & 44 & 81.4 \\
\hline
\end{tabular}

These results reflect continuing commitment to the quality standards that are the backbone of cataloging. As librarians continue to adhere to the established standards, they develop new standards to accommodate the new formats and material types.

Participation in the Library of Congress Cooperative Cataloging Programs (PCC) is generally considered by many to be an indication of commitment to quality that the library community expects. Most ARL libraries responding to the survey are actively participating in one or more of the Library of Congress PCC programs. Table 2 shows that the largest number of respondents (59.2 percent) indicated that they are contributing authority records to the Name Authority Cooperative Program of the PCC (NACO), while 31 percent are contributing their records to the Monographic Bibliographic Records Program (BIBCO). Another 29.6 percent are contributing records to the Subject Authority Cooperative Program (SACO), and 20.3 percent are participating in the Cooperative Online Serials (CONSER). Nearly a half of the respondents (40.5 percent) indicated that they are not members and are not contributing to the PCC Program at this time.

Libraries are not likely to change their participation in PCC programs, as their collections 
are being made available through the Internet. As Table 3 demonstrates, a majority of libraries responded to this question with a lot of doubt. Nearly one in three libraries (29.6 percent) indicated that they would participate or continue participating in NACO, 20.3 percent will participate or continue participating in $\mathrm{BIBCO}, 20.3$ percent will participate or continue participating in SACO, and 18.5 percent would participate or continue participating in CONSER. Five libraries commented that they are thinking of participating and it is in their future plan, while three libraries felt that Open WorldCat would increase the pressure on libraries to perform high quality cataloging to assure patron access to all materials. Most of the comments indicated that libraries do not have enough qualified staff nor the time to go through the Library of Congress quality review in order to become members in these programs.

Table 2. Is your Library a Member of the Library of Congress International Program for Cooperative Cataloging?

\begin{tabular}{||r||r|r||r|r||}
\hline \multirow{2}{*}{} & \multicolumn{2}{|c|}{ Yes } & \multicolumn{2}{c|}{ No } \\
\cline { 2 - 5 } & \multicolumn{1}{|c|}{$\boldsymbol{N}$} & \multicolumn{1}{c|}{$\%$} & \multicolumn{1}{c|}{$\boldsymbol{N}$} & \multicolumn{1}{c|}{$\%$} \\
\hline NACO & 32 & 59.2 & 22 & 40.5 \\
\hline \hline BIBCO & 17 & 31 & 37 & 67.5 \\
\hline SACO & 16 & 29.6 & 38 & 70.3 \\
\hline \hline CONSER & 11 & 20.3 & 43 & 79.6 \\
\hline None & 22 & 40.5 & 32 & 59.2 \\
\hline
\end{tabular}

Table 3. Will the Potential Visibility in Opening WorldCat Create the Need for Your Library to Participate in the Library of Congress International Program for Cooperative Cataloging (PCC) for Providing More Quality Content?

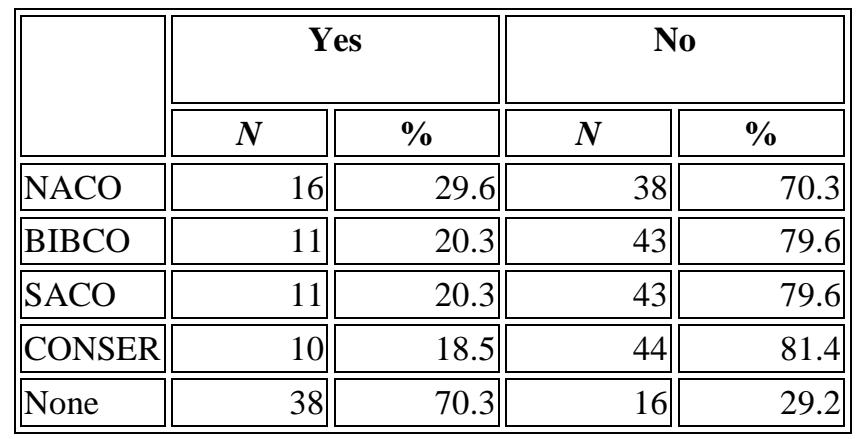

\section{Staffing Levels}

One of the ways to assess quality of cataloging is to look at how libraries handle the staffing issue and staff training. The question in Table 4 was designed to measure the level of staffing assigned to cataloging in the ARL libraries and ways in which cataloging tasks are being assigned to various staff levels. All respondents (100 percent) as shown in Table 4, indicated that they are using librarians to perform original cataloging, complex copy cataloging, cataloging of 
foreign language materials, some incomplete copy, copy needed subject headings and call number, and cataloging of various formats.

Table 4 also demonstrates that all responding libraries (100 percent) are utilizing paraprofessionals in cataloging. Although some of the responses did not specify which specific tasks are assigned to paraprofessionals, responses from other libraries indicated that paraprofessionals are performing copy cataloging, simple original cataloging, such as new edition, variant edition, and original cataloging for theses.

Table 4. Who does the Cataloging in your Library?

\begin{tabular}{|l||r||r|}
\hline & \multicolumn{1}{|c|}{$N$} & \multicolumn{2}{|c|}{$\%$} \\
\hline \hline Librarians & 54 & 100 \\
\hline Para-professional & 54 & 100 \\
\hline Students assistants & 23 & 42.5 \\
\hline Vendor (specify) & 35 & 64.8 \\
\hline
\end{tabular}

Although only 42.5 percent of respondents indicated that their libraries are using student assistants, it was very important to see how libraries are using students and what kind of tasks they are performing. Some respondents indicated that they are using students to perform simple copy cataloging, processing of records with DLC, doing copy cataloging of non-roman languages, checking, cataloging electronic resources, and materials that need vernacular.

The practice of using non-professional staff or graduate student assistants in cataloging is fairly common among academic libraries. As these libraries strive to maintain high quality of cataloging, it becomes necessary for them to provide a level of training that would allow these libraries to continue to adhere to those cataloging standards discussed in the preceding section.

\section{Vendor Services}

Table 4 also shows that nearly two-thirds ( 64.8 percent) of the respondents indicated that they are using vendor services for part of their cataloging. As libraries are taking advantage of vendor services, they need to pay particular attention to record quality. The survey mentions a variety of vendors that are being used. Librarians provided comments on what vendor services they are currently using as follows: 17.1 percent (six) indicated that they are using YBP Library Services; 17.1 percent (six) are using MARCIVE, Inc. for obtaining bibliographic records for Government Documents and other cataloging services; 25.7 percent (9) are using OCLC PromptCat services; 14.2 percent (five) are using OCLC TECHPRO for cataloging foreign languages, such as Arabic and CJK (Chinese, Japanese, and Korean materials); 8 percent (three) are using Shelf Ready; 11.4 percent (four) are using Blackwell; 5 percent (two) are using Backstage Library Works, and one library is using EBSCO services. One library also indicated that they would increase vendor services while other libraries mentioned that they are purchasing record sets for electronic resources and microforms. 
This part of the survey reveals that ARL libraries continued to use mixed methods to satisfy their cataloging needs. In most cases, a combination of in-house cataloging is augmented by contracts with outside vendors. In-house cataloging is conducted by professional catalogers, with the assistance of paraprofessional staff and student assistants. However, professional catalogers and paraprofessionals constituted the foundation of cataloging in most institutions.

At this time, libraries are not planning to hire new professional staff for the purpose of enriching their cataloging records (Table 5). In responding to this question, 50 percent of respondents indicated that they were not sure if library administrations would create additional cataloger position solely for the purpose of enriching their cataloging records. The second largest groups of respondents (44.4 percent) indicated that they would not hire new catalogers or staff. Some of the responses seem to reflect the fact that technical service operations have been understaffed for a long time and that libraries are not showing willingness to go back and rebuild staffing in this area.

Table 5. If your Library Decides to Enrich Records Added to WorldCat, Are you Planning to Add More Professional Catalogers to Your Staff?

\begin{tabular}{|l|r||r||}
\hline & \multicolumn{1}{|c|}{$\boldsymbol{N}$} & \multicolumn{2}{|c|}{$\%$} \\
\hline \hline Yes & 3 & 5.5 \\
\hline \hline No & 24 & 44.4 \\
\hline \hline Not sure & 27 & 50 \\
\hline
\end{tabular}

Table 6. Do you Expect the Decision to Open WorldCat to Increase The Cost of Cataloging?

\begin{tabular}{||l|r||r||}
\hline & \multicolumn{1}{|c|}{$\boldsymbol{N}$} & \multicolumn{1}{c|}{$\%$} \\
\hline Yes & 4 & 7.4 \\
\hline No & 44 & 81.4 \\
\hline Not sure & 6 & 11 \\
\hline \hline
\end{tabular}

One respondent expressed a concern that shortage of professional librarians would definitely affect the quality of cataloging records, and negatively impact access to information. However, a very small percentage of the responses ( 5.5 percent) mentioned that they would add more staff, but not necessarily librarians, if they had to enrich their bibliographic records.

In view of the response to the question above, the issue of increased cost of cataloging as a result of hiring additional staff and enriching bibliographic records seemed less relevant (Table 6). Most libraries (81.4 percent) did not anticipate any increase in the cost of cataloging. A small percentage (11 percent) indicated in their responses that they are not sure if the cost of cataloging will increase, while 7.4 percent thought that there would be an increase in the cost related to the time spent in cataloging and enriching bibliographic records in addition to hiring of additional staff.

Some of the comments addressed the increases in the cost of cataloging related to how much additional time libraries would need to spend on enriching bibliographic records and the 
level of staffing involved in the process. Some respondents mentioned that enrichments of the bibliographic records would slow the overall production and raise the cost of cataloging. Adding new librarians would have an impact on the overall cost as well. Some librarians emphasized the importance of producing high quality records and how this impacts the overall costs: "if you do it right from the beginning, this will save money and time to fix it."

\section{Part Two: Un-cataloged Collections}

Many libraries have treasure troves of materials in special collections, un-cataloged backlogs, archives and manuscript repositories that are often not fully represented in the library OPAC. They are used locally and available to walk-in patrons only. Parts of these collections have been digitized and locally cataloged. Libraries are now faced with the opportunity to make these rare collections available through the Internet. This would involve commitment of energy and resources, and the survey raises important questions about where libraries stand on this issue.

In this section, the author will attempt to broadly identify the types of un-cataloged collections held at the surveyed libraries and to establish if libraries are making plans to have these collections cataloged.

In Table 7, nearly 90 percent of all respondents indicated that they have significant uncataloged collections, while 11 percent mentioned that they have no un-cataloged materials. In addition to new receipts un-cataloged materials, some libraries have backlogs that are related to retrospective conversion, gift collections, pre-1976 government documents, rare collections, microforms that need analytics, and archival materials.

The question in Table 8 was designed to provide detailed information about the types of un-cataloged materials held by the ARL libraries. Responses to this question provide a rich data set that deserves further study. A number of libraries reported that they have sizable special collections materials (e.g. ca. 60,000 rare books), while another group reported significant foreign language un-cataloged materials, mainly in Japanese. Gift collections, collections of slides, and microforms constitute significant subsets of un-cataloged materials as well. It is important to emphasize that most of these un-cataloged materials are not present in the OCLC or RLIN databases, and most have no records in local library online catalog systems.

Although the design of question 9 did not require the respondents to provide direct information about their plans to catalog the un-cataloged materials in their libraries, most of respondents expressed their wish to catalog all of their materials. This conveys a sense of urgency about the need to have these materials made available to the public as soon as possible.

The question was directed at the issue of methods that might be employed to catalog these collections. As Table 9 indicates, the answers were diverse. Nearly half (48 percent) of respondents chose collection level cataloging for handling specific collections, such as archival materials and manuscripts. One library mentioned that they will be using collection level cataloging for some materials, but they will not add bibliographic records to the OCLC WorldCat. More than one third (35 percent) of the responding libraries plan on using short/ brief bibliographic records, especially "K" level for outsourcing materials such as maps. Other respondents indicated that they would input brief records with no subject headings. Three fourths of libraries (75.5 percent) responded that they will be cataloging at full bibliographic level whenever possible. One respondent indicated that their library decided to use full bibliographic records for un-cataloged foreign language materials. Others responded that they would be using 
this approach for cataloging serials and electronic monographs.

One of the important questions in this part of the survey dealt with the issue of how libraries would deal with hidden collections once their catalogs became available through the Internet (Table 10). The response to this question was neutral. Nearly 45 percent of the respondents indicated that they already experience some pressure to catalog their hidden collections and that these materials need to be in circulation. Increased visibility resulting from opening their collections through Open WorldCat did not seem to be a factor here.

Table 7. Does your Library have Un-cataloged Collections?

\begin{tabular}{|l|r|r|}
\hline & \multicolumn{1}{|c|}{$\boldsymbol{N}$} & \multicolumn{1}{|c|}{$\%$} \\
\hline \hline Yes & 48 & 88.8 \\
\hline \hline No & 6 & 11 \\
\hline
\end{tabular}

Table 8. What Kind of Un-cataloged Collections does your Library have?

\begin{tabular}{||l||r||r||r|r||}
\hline \multirow{2}{*}{} & \multicolumn{2}{|c|}{ Yes } & \multicolumn{2}{|c|}{ No } \\
\cline { 2 - 5 } & \multicolumn{1}{|c|}{$N$} & \multicolumn{1}{c|}{$\%$} & \multicolumn{1}{|c|}{$N$} & \multicolumn{1}{c|}{$\%$} \\
\hline Western language print new receipts & 11 & 20.3 & 43 & 79.6 \\
\hline Western language print retrospective conversion & 17 & 31.4 & 37 & 68.5 \\
\hline Non-Roman language print new receipts & 18 & 33.3 & 36 & 66.6 \\
\hline Non-Roman language retrospective conversion & 4 & 7.4 & 50 & 92.5 \\
\hline \hline Western language special formats & 22 & 40.7 & 23 & 59 \\
\hline Non-Roman language special formats & 6 & 11 & 49 & 90.7 \\
\hline \hline Electronic resources (e.g. Web site) & 11 & 20.3 & 43 & 79.6 \\
\hline Special collections materials & 22 & 40.7 & 23 & 59 \\
\hline \hline
\end{tabular}

Another 46.2 percent responded that the Open WorldCat has nothing to do with cataloging their hidden collections or with the visibility of their library or their collections. These institutions would continue what they are doing now and there would be no additional efforts or plans to do more than what is being done currently. About 10 percent of the respondents indicated that they were not certain of how Open WorldCat would affect their efforts to catalog their hidden collection. Many comments received with the survey emphasize the need to have important library collections made available to users regardless of how Open WorldCat might impact the library.

This response reveals a basic uncertainty about how most librarians view the Open WorldCat initiative and the way it might impact libraries. It seems that implications of this change are difficult to predict and libraries are not taking additional steps at this time to accommodate this development. 
Table 9. If you are Making Plans to Catalog your Un-Cataloged Collection, Which Methods are you Likely to Use to Catalog and Add these Collections to WorldCat?

\begin{tabular}{|c|c|c|c|c|}
\hline & \multicolumn{2}{|c|}{ Yes } & \multicolumn{2}{|c|}{ No } \\
\hline & $N$ & $\%$ & $N$ & $\%$ \\
\hline Collection -level record & 26 & 48 & 28 & 51.8 \\
\hline Short/brief record (e.g. "K" level record) & 19 & 35 & 35 & 64.8 \\
\hline Full bibliographic records & 41 & 75.5 & 13 & 24 \\
\hline Other specify & 0 & 0 & 0 & 0 \\
\hline
\end{tabular}

Table 10. Does the Potential Visibility in Open WorldCat Encourage your Library to Catalog "Hidden" Collections?

\begin{tabular}{|l||r||r|}
\hline & \multicolumn{1}{|c|}{$\boldsymbol{N}$} & \multicolumn{1}{c|}{$\%$} \\
\hline Yes & 24 & 44.4 \\
\hline No & 25 & 46.2 \\
\hline Not sure & 5 & 9.2 \\
\hline
\end{tabular}

Until now, many libraries excluded parts of their collections from their OPACs. The question whether or not libraries will exclude some records from WorldCat after it becomes available through Google was raised in Table 11. Nearly three out of four libraries answered this question in the negative. Only 9.2 percent of respondents indicated that they would be excluding materials from WorldCat. Some of the materials that would be excluded are theses and dissertations, electronic theses and dissertations (ETDs) that are embargoed for patents, U.S. depository materials, passworded materials, materials that are required to be excluded by the vendor, license-restricted materials, and materials not available for document delivery. However, 16.6 percent of respondents indicated that they have not made a decision about this issue at this time. The response to this question suggests that many librarians would like to have more of their collections available through the Internet.

Information available to Internet users is typically much richer than what is available in a bibliographic database such as WorldCat or a library OPAC. Survey question 12 raised the issue of record enrichment and how libraries are planning to accomplish this task. Table 12 shows that 20.2 percent of responding institutions plan on providing some enrichment to bibliographic records as a result of the Open WorldCat initiative. However, two thirds ( 66.6 percent) of the respondents indicated that they would not enrich their bibliographic records as a result of Opening of the WorldCat. The remaining 15 percent of respondents were not sure if they would enrich their bibliographic records.

Some of the respondents commented that libraries would provide enhancements to their bibliographic records not because of the Open WorldCat initiative, but to provide quality access 
to their own users. They expect to perform these enhancements locally into their OPAC. One respondent mentioned that their institution is adding tables of contents to some materials locally, while another mentioned that they are adding more descriptions and details to their special collections materials. Some other libraries plan to add more access points to their bibliographic records, if they have more staff. Others indicated that the issue of enhancing or enriching of bibliographic records has not been discussed in their libraries until now.

Table 11. Will Your Library Attempt to Exclude Some Records from WorldCat After it Becomes Available Through Google?

\begin{tabular}{|l|r||r|}
\hline & \multicolumn{1}{|c|}{$\boldsymbol{N}$} & \multicolumn{1}{c|}{$\%$} \\
\hline Yes & 5 & 9.2 \\
\hline No & 40 & 74 \\
\hline \hline No decision & 9 & 16.6 \\
\hline
\end{tabular}

Table 12. Since Users will be Remotely Evaluating an Item Through Information Recorded in the Bibliographic Records, Is your Library Likely to Provide Enrichments to The Bibliographic Records?

\begin{tabular}{|l|r|r|}
\hline & \multicolumn{1}{|c|}{$N$} & \multicolumn{1}{|c|}{$\%$} \\
\hline \hline Yes & 11 & 20.2 \\
\hline No & 36 & 66.6 \\
\hline \hline Not sure & 8 & 15 \\
\hline
\end{tabular}

A number of librarians gave a clear indication that their library would not automatically enhance all cataloging records in the new environment. It was mentioned that libraries would select records to be enhanced based on the collection being cataloged and available resources.

Survey participants who responded "yes" to question 12 specified what kind of enrichments they would provide to their bibliographic records in Table 13. About 9 percent indicated that they would add abstracts, 16.6 percent would add tables of contents, 11 percent would add summaries when it is appropriate, and 5.5 percent would add key words. Some of the comments indicated that libraries would be willing to add more information to their records if that information was easily available from vendors. Libraries would consider purchasing more tables of contents, for example. One respondent mentioned that they already subscribe to the Blackwell North America (BNA) table of contents service, but they add these contents only locally. Other librarians indicated that they are exploring various ways of enriching their bibliographic records. Some libraries began to add abstracts and key words to their special collections and theses and dissertations. One library indicated that they are already adding reviews and links about author information to their bibliographic records. A feeling of ambiguity and a certain lack of clear direction are evident from answers to most of the questions in this section. Libraries responding to the survey do not seem to be making special preparations or plans that might address issues that might be expected to arise from the Open WorldCat initiative. Survey responses convey the sense that it is too soon to anticipate what 
demands or requirements will be raised by the "Google generation" of information users. Table 13. If you Answered Yes to Question Number 12, What Kind of Information Would your Library Add to the Bibliographic Record?

\begin{tabular}{|c|c|c|c|c|}
\hline & \multicolumn{2}{|c|}{ Yes } & \multicolumn{2}{|c|}{ No } \\
\hline & $N$ & $\%$ & $N$ & $\%$ \\
\hline Abstracts & 5 & 9.2 & 49 & 90.7 \\
\hline Table of contents & 9 & 16.6 & 45 & 83.3 \\
\hline Summaries & 6 & 11 & 48 & 88.8 \\
\hline Keywords & 3 & 5.5 & 51 & 994.4 \\
\hline
\end{tabular}

Table 14. Libraries are Now Engaged in Creating Local Repositories of Digital Items that are Kept Silos. Some of these are Available Online and Can be Searched by Google, Yahoo!, etc. Does your Library have such a Repository?

\begin{tabular}{|l|r|r|}
\hline & \multicolumn{1}{|c|}{$\boldsymbol{N}$} & \multicolumn{1}{c|}{$\%$} \\
\hline Yes & 29 & 53.7 \\
\hline No & 17 & 31.4 \\
\hline Planning & 8 & 15 \\
\hline
\end{tabular}

\section{Part Three: Institutional Repositories}

Another important decision facing library managers is the issue of integrating institutional repositories of digital contents with library OPACs. Many institutions have been experimenting with digital repositories, while some are just in the planning stages. The last part of the survey attempts to determine how libraries are dealing with this issue now and what plans they are making for the future.

Survey responses confirmed that building an institutional repository is a priority for most major institutions. Table 14 revealed that most of the ARL libraries that participated in this survey (53.7 percent) are already engaged in creating local repositories for digital resources, while another 15 percent indicated that they are in the planning stage. Nearly one-third (31.4 percent) of the respondents indicated that they are not creating such a repository at the present time.

One of the issues facing a typical repository is the absence of consistent selection policies. Contents of institutional repositories are varied from one institution to another not only in content, but also in ways they are integrated with the local library. Table 15 shows that out of twenty-nine of the libraries that indicated the presence of a repository at their institution, twentyone (72.4 percent) provide partial access to the repository collection through their OPAC system. Typical collections include EDTs, digitized print collections only (not images), and honors theses. Among the twenty-one libraries that provide access, four indicated that they are providing 
access to the repository collection by creating collection level records or complete bibliographic records. The remaining eight (27.5 percent) respondents indicated that their libraries do not provide access at this point but they are reviewing their selection criteria for inclusion in their OPACs. Two of the eight libraries commented that that they are using their Web sites and DSpace for accessing their repository collections.

Table 15. If Yes, does your Library also Provide Access to the Repository Contents Through the OPAC?

\begin{tabular}{|l|r|c|}
\hline & \multicolumn{1}{|c|}{$\boldsymbol{N}$} & \% \\
\hline Yes & 21 & 72.4 \\
\hline No & 8 & 27.5 \\
\hline
\end{tabular}

Table 16. Does your Library also Provide Access to the Repository Contents Through Bibliographic UtilitiTable 16. Does your Library also Provide Access to the Repository Contents Through Bibliographic Utilities such as OCLC and RLIN?

\begin{tabular}{||r||r||r|}
\hline & \multicolumn{1}{|c|}{$N$} & \multicolumn{1}{|c|}{$\%$} \\
\hline \hline Yes & 20 & 68.9 \\
\hline No & 3 & 10 \\
\hline Planning to provide access & 6 & 20.6 \\
\hline
\end{tabular}

Many of the institutions that already have repositories did not perceive the need to add all of their repository records to OCLC or RLIN. Table 16 reveals that although more than two thirds of the libraries surveyed (68.9 percent) are adding records to the bibliographic utilities (16 OCLC and 1 RLIN), they are adding records of only selected collections, such as ETDs, fiction collections, etc. A majority of repository records added to OCLC or RLIN are collection level records. Three of the twenty libraries that add their repository records to OCLC or RLIN indicated that everything in the repository/OPAC is also represented in OCLC.

Ten percent of all respondents indicated that they are not planning to add their repository records to any of the bibliographic utilities. These respondents felt that cataloging of these materials and adding them to the catalog would prove to be too costly and redundant, given the fact that these materials are already indexed and accessible through the major search engines such as Google and Yahoo! Another 20.6 percent indicated that they are planning to add some of their repository collections to OCLC at a future time.

Most libraries indicated in Table 17 that their repositories include mixed collections. (Please note that not all the repositories include all of these categories.)

Data regarding the repository collections reveal that most libraries do not perceive the need to fully integrate their repository and library holdings. This phenomenon is likely to influence the overall effectiveness of the effort to integrate library resources with the information superhighway. 
Table 17. If Yes, Could you provide a General Description of Materials Held in your Repository?

\begin{tabular}{|l||}
\hline Theses/dissertations and honors theses \\
\hline \hline Archival collections, papers, working papers, letters, interviews, photographs, reports, technical reports \\
\hline \hline Article pre- and post-prints \\
\hline \hline Electronic journals and electronic books, open access journals, locally published electronic journals \\
\hline Textual objects, graphical objects, and multimedia. \\
\hline Digitized materials from Peel's Prairie Provinces bibliography and related materials \\
\hline Slides of historic landscape architecture, university photographs, and photos of Iowa barns \\
\hline $\begin{array}{l}\text { Faculty publications (results of faculty research, departmental papers from across campus, faculty research } \\
\text { output, faculty research materials) }\end{array}$ \\
\hline University publications and archival materials \\
\hline Specific manuscript collections in digitized form, special collections, and unique materials \\
\hline Locally digitized work; pre-prints, post-prints \\
\hline $\begin{array}{l}\text { TEI text collections (largely Americana-American South, Virginia, American fiction (pre 1923); a } \\
\text { collection of EAD finding aids for large image collection (images used for teaching) }\end{array}$ \\
\hline
\end{tabular}

Table 18. If not, do you Envision a Future when all Library Contents will be Digitized and Available Electronically in Full Text?

\begin{tabular}{||l|r||r|}
\hline & \multicolumn{1}{|c|}{$\boldsymbol{N}$} & \multicolumn{1}{c|}{$\%$} \\
\hline \hline Yes & 11 & 20.2 \\
\hline No & 28 & 51.8 \\
\hline Not sure & 15 & 27.7 \\
\hline
\end{tabular}

\section{Part Four: Digitizing Library Collections}

Many of the survey respondents expressed considerable restraint in their appraisal of this development. This can be attributed in part to some level of skepticism toward the concept of a digital library. When asked to envision a future when all library content will be digitized and available electronically (Table 18), 20.2 percent of respondents indicate that they see some potential for this, but not in the next few years. More than half (51.8 percent) responded that it will be impossible to digitize all library collections; however, 27.7 were not sure and they do not see this happening in the near future.

Most of the respondents indicated that money would be an issue when it came to digitizing library collections and many had questions about sources of funding. Some felt that perhaps commercial support (such as Google) would make this possible. There was also great concern about copyright laws that would likely be an obstacle to full digitization. Most of the comments indicated that libraries would not digitize their entire collections, but perhaps large parts. Respondents offered comments such as these: "Probably not in the foreseeable," "All? no; most- yes, but several decades ahead," "A large percentage, perhaps, but not all," "possibly 
digitization on demand; but not comprehensive," "Very unlikely that ALL contents will be digitized," "maybe not all, but a lot will be," "At least not for some years due to legal issues."

Many respondents to this question found it difficult to envision a future where all library collections would be digitized. They predicted that some selected materials would be digitized, but not all. Copyright and budgets seemed to be the greatest obstacles. A few respondents commented that print materials would stay with us for a long time. It seems that there is still demand for paper and not everyone uses the Internet.

\section{Conclusion}

The findings of this survey provide important insights into the way ARL library administrators perceive the OCLC Open WorldCat initiative and how they are preparing to handle the potential impact of this new development. Although the prospect of making library collections visible to the whole world via the Internet is likely to have a significant effect on libraries, the survey reveals a rather cautious attitude. Responses to survey questions strongly suggest that most of the ARL libraries are not anticipating immediate preparations to address issues that have not yet fully emerged. This generally guarded approach to the concept of a digital library is reflected in answers to many of the questions in the survey. An explanation for this rather cautions response can be viewed from a number of perspectives suggested by the survey respondents themselves. Realities of library operations are such that no new funding is being made available to provide special treatment to materials going into Google via the Open WorldCat. Enhancements that are currently being made to some bibliographic records will continue to be made in response to the need to serve all clients, regardless of how they access these materials.

Regardless of how one estimates the relative importance of Google and other search engines to the overall research process, it can be generally acknowledged that no search engine can locate items in libraries without reliance on cataloging records that will point to the object that is being sought. In order to facilitate an effective search, these cataloging records, whether we call them metadata or something else, will have to be based on consistently applied standards that will describe each item going into an OPAC, a Silo, a digital archive or any other storage device. Most librarians responding to the survey remain committed to those cataloging standards that provide consistency of catalog records. Most of the respondents felt that these records will have to be consistent, complete, and accurate. Participation in the Library of Congress programs seems to confirm the need to maintain accepted standards developed and maintained by a responsible body.

The Open WorldCat initiative does not seem to be resulting in a major change in library operations at this time. Library administrators are discussing its impact, but remain focused on continuing to deliver quality services to their own constituents. This study brought together and analyzed important data at the time when the Open WorldCat initiative is being implemented. It also recorded the state of the libraries at this important juncture.

Mid-level and upper-level library administrators that responded to this survey perceive the need to provide access to library materials, based on priorities dictated by immediate need as expressed by their own users, and locally available resources. The Open WorldCat initiative has yet to send strong signals that something specific needs to be done. These signals will most likely emerge in the near future, when some statistical data will become available. This will offer 
an excellent opportunity to evaluate the real impact of the Open WorldCat initiative on the Internet user. Such data will also provide opportunities to study the impact that the WorldCat database is having on the Internet and its users.

Acknowledgment: The authors wish to thank George Klim for reading this article and making valuable comments.

\section{Appendix A: Survey}

1. What cataloging standards does your library use for cataloging?
a. AACR2 rev LCSH
b. LC Classification
c. DDC
d. UDC
e. MARC 21
f. Functional Requirements for Bibliographic Records
g. (FRBR)
h. Dublin Core
i. Comments

2. Is your library a member of the Library of Congress International Program for Cooperative Cataloging?
a. $\mathrm{NACO}$
b. BIBCO
c. SACO
d. CONSER
e. Comments

3. Will the potential visibility in open WorldCat create the need for your library to participate in the Library of Congress International Program for Cooperative Cataloging (PCC) for providing more quality control in your records?
a. NACO
b. BIBCO
c. SACO
d. CONSER
e. Comments

4. Who does the cataloging in your library?
a. Librarians
b. Par-professions
c. Student assistants
d. Vendors (please specify)
e. Comments

5. If your library decides to enrich records added to WorldCat, are you planning to add professional cata-logers to your staff?

a. Yes 
b. No

6. Do you expect the decision to open WorldCat to increase the cost of cataloging?
a. Yes
b. No
c. Comments

7. Does your library have un-cataloged collections?
a. Yes
b. No
c. Comments

8. What kind of un-cataloged collections does your library have?

a. Western language print new receipts (please specify)

b. Western language print retrospective conversation (please specify)

c. Non-Roman language print new receipts (please specify)

d. Non-Roman language print retrospective conversion (please specify)

e. Western language special formats (please specify)

f. Non-Roman language special formats (please specify)

g. Electronic resources (e.g. Web sites) (please specify)

h. Special Collections materials (please specify)

i. Comments

9. If you are making plans to catalog your un-cataloged collections, which methods are you likely to use to catalog and add these collections to WorldCat?
a. Collection-level record
b. Short/brief record (e.g. K level record)
c. Full bibliographic record
d. Others (Please specify)
e. Comment

10. Does the potential visibility in open WorldCat encourage your library to catalog 'hidden' collections?
a. Yes
b. No
c. Comments

11. Will your library attempt to exclude some records from WorldCat after it becomes available through Google?
a. Special materials (e.g. thesis and dissertations
b. Special Formats
c. Expensive materials
d. Comments

12. Since users will be remotely evaluating an item through information recorded in the bibliographic record, is your library likely to provide enrichments to the bibliographic 
record?
a. Yes
b. No
c. Comments

13. If you answered yes to question number 12, what kind of information would your library add to the bibliographic record?
a. Abstracts
b. Table of contents
c. Summary
d. Key words
e. Others (please specify)
f. None
g. Comments

14. Libraries are now engaged in creating local repositories of digital items that are kept in silos. Some of these are available online and can be searched by Google, Yahoo, etc. Does your library or institution have such a repository?
a. Yes
b. No
c. Comments

15. If yes, does your library also provide access to the repository contents through your OPAC?
a. Yes
b. No
c. Comments

16. Does your library also provide access to the repository contents through the bibliographic utilities such as OCLC and RLIN?
a. Yes
b. No
c. Comments

17. Could you provide a general description of materials held in your repository?

18. If not, do you envision a future when all library contents will be digitized and available electronically in full text?
a. Yes
b. No
c. Comments

19. What is the approximate size of your library?
a. Under 500,000
b. $500,000-1,000,000$ 
c. $1,000,000-3,000,000$

d. $3,000,000-5,000,000$

e. Above 5,000,000 Comments

20. What utility does your library use for cataloging?
a. OCLC
b. RLIN
c. Others (please specify)

21. Please identify yourself and your institution?

\section{APPENDIX B: INVITATION}

\section{Dear Colleagues,}

I am writing to ask you to participate in a very brief survey on the impact of open WorldCat and accessing materials remotely in ARL libraries. You were chosen as the most obvious person in your organization to answer a few short questions about the impacts in your library or libraries. If you are not the appropriate person to answer these questions, please pass along this message to another person in your library. I realize that many libraries have complex organizational structures and functions may take place in many departments.

This brief survey is intended to address the question of the impact of open WorldCat and accessing materials remotely. There are only twenty-one questions which should take fewer than ten minutes to reply.

If you prefer, I would be happy to send a paper copy in the mail so that it could be completed without using electronic communications, or to send the survey as an e-mail attachment. In any case, the responses will be kept confidential and will not be associated with any individual institution.

I appreciate your willingness to participate in this research project, and I thank you in advance for your time. Please feel free to contact me if you have any specific questions. I plan to publish my results, and would also be happy to discuss the project in more detail.

Magda El-Sherbini

Head, Cataloging Department

Ohio State University Libraries

http://www.zoomerang.com/survey.zgi?p=U244C4LGE9AR

\section{Notes and References}

1. Stephen Abram, "The Google Opportunity," Library Journal (February 1, 2005). Available: http://www.libraryjournal.com/ article/CA498846.html (Accessed June 6, 2006).

2. Judy Luther, "Google? Metasearching's Promise," Library Journal (October 1, 2003). Available: http://www.libraryjoumal.com/ article/CA322627.html (Accessed June 6, 2006).

3. "RedLightGreen." Available: http://www.rlg.org/en/page.php? Page_ID=433 and 
dataGo.x=1 1 \&dataGo.y=1 3 (Accessed May 22, 2006).

4. Barbara Quint, "OCLC Project Opens WorldCat Records to Google," InfoToday News Breaks (October 27, 2 003). Available: http://www.infotoday.com/newsbreaks/nb0310272.shtml (Accessed June 6, 2006).

5. Barbara Quint, "Yahoo! Search join OCLC Open WorldCat project," InfoToday News Breaks (July 6, 2004). Available: http:// www.infotoday.com/newsbreaks/nb0407062.shtml (Accessed June 6, 2006).

6. Barbara Quint, "All of OCLC's WorldCat Heading Toward the Open Web," InfoToday News Breaks (October 11, 2004). Available: http://www.infotoday.com/newsbreaks/nb04101 1-2.shtml (Accessed June 6, 2006).

7. "RLG to Combine with OCLC." Available: http://www.oclc.org/ news/releases/200618.htm (Accessed June 6, 2006).

8. "Open WorldCat Program." Available: http://www.oclc.org/ worldcat/open/default.htm (Accessed June 6, 2006).

9. "Quick Facts about the Open WorldCat Pilot." Available: http:// www.oclc.org/worldcat/open/facts/default.htm (Accessed June 7, 2006).

10. "How the Open WorldCat Program Works." Available: http:// www.oclc.org/worldcat/open/how/default.hnn (Accessed June 7, 2006).

11. "Open WorldCat Pilot: Frequently Asked Questions." Available: http://www.oclc.org/worldcat/open/faq/defaull.htm (Accessed June 7, 2006).

12. "User-Contributed Content Pilot." Available: http://www. oclc.org/worldcat/open/features/default.htm (Accessed June 7, 2006).

13. David Mattison, "RedLightGreen and Open WorldCat: Changing the World of Academic Search," Searcher 13 (4) (April 2005): 14-23. Available: http://web.ebscohost.com/ehost (Accessed October 17, 2006).

14. Nancy O'Neill, "Open WorldCat Pilot: a User's Perspective," Searcher 12 (10) (November/December 2004). Available: http://www. infotoday.eom/searcher//nov04/oNeill.shtml (Accessed June 7, 2006); Gary Price, "Web Search-Yahoo! News Breaks: Two Million Open WorldCat Hit the Yahoo! Database," ResourceShelf (Wednesday, July 7, 2004). Available: http://www.resourceshelf.com/2004/07/ two-million-open-worldcat-records-hit.html (Accessed June 6, 2006); Gary Price, "Open WorldCat: Subject Headings Now Hyperlinked in Open WorldCat," ResourceShelf (Wednesday, November 10 2004). Available: http://www.resourceshelf.com/2004_1l_01_resourceshelf_archive.html (Accessed June 6, 2006).

15. Gary Price and Steven M. Cohen, "OCLC Opens up the Complete WorldCat Database to Web Engines and Other Partners," ResourceShelf (October 11, 2004). Available: http://www.resourceshelf. com/2004_10_01_resourceshelf_archive.html (Accessed June 6, 2006).

16. Paula Wilson, "Open WorldCat: Earth's Largest Library," Public Libraries (2005 (MarchApril)): 82-83.

17. "Association of Research Libraries." Available: http://www.arl. org/members.html (Accessed June 6, 2006). 